This is a pre-copyedited, author-produced version of an article accepted for publication in the Journal of Material Culture

\title{
Living with the Past at Home: the afterlife of inherited domestic objects
}

\section{Caron Lipman}

Introduction

Many people live in pre-inhabited homes, the intimacy of domestic dwelling mediated by varying degrees of awareness that their home has been the residence of prior occupants whose traces remain in its physical fabric and in the objects left behind. This mundane presence of the past suggests alternative practices to the more purposeful unearthing of historic things; a fragmented inheritance of left behind residues often inadvertently discovered in the process of refurbishment. Names and dates are scored onto walls under layers of wallpaper; small objects - toys, coins, beads - are found under floorboards, in attics, jammed-up drawers, or in garden soils, whilst its material fabric, decorative details, form, layout and structure more overtly writes the home's histories across its surfaces. This essay will explore this ubiquitous but overlooked aspect of domestic life, based on insights from a project which has involved interviews with members of thirty five households living in a range of English homes of different ages, locations and tenures.

Popular guides stress the importance of discarded or forgotten objects left over by previous inhabitants as offering clues to the house's past. This evokes forms of excavation that parallel recent interest in extending archaeological practice to contemporary contexts including homes, to consider the social conditions and effects of historical artefacts (Buchli and Lucas, 2001, Owens et al, 2010, Jeffries et al 2009). Turning the focus on the making and meaning of the past away from the public to the private sphere, this essay aims to highlight the home as a site of historical imagination, knowledge and practice. By following the 'afterlife' of domestic inheritance, I will explore the choices inhabitants make - the acts of leaving, removing or replacing past materials - and what these reveal of the meanings granted to the domestic past and its objects, and the beliefs and values underpinning such practices.

Attitudes to the residues of pre-habitation can be explored alongside work considering objects as 'generat [ing] social effects not just in their preservation and persistence, but in their destruction and disposal' (DeSilvey 2006: 324), drawing on a recent focus on the practices of consumption and divestment of household consumer products, second hand objects and waste things (see Marcoux 2001, Miller 2001, Gregson and Crewe 2003, Gregson, Metcalfe and Crewe 2007, Lucas 2002, Grossman 2015, Digby 2015, Hetherington 2004). These interventions are paralleled by everyday senses of the meaning of left-behind objects as once embedded in webs of social relations and as material connections with past, as well as future, occupants. This becomes important in the light of recent scholarship emphasising ways in which the home and its objects express and constitute the self (Blunt and Dowling 2006, Varley 2008, Tolia-Kelly 2004, Miller 2008, Fortier 2000, Marcus 1995, hooks 1990). The act of homemaking is fuelled by a desire to develop senses of belonging, privacy and familiarity; these ideal tropes attached to the idea of home continue to resonate, despite being unavailable to many. Objects of personal value or memory are often galvanised as part of the homemaking project, reflecting or reinforcing senses of belonging and familiarity to enhance feelings of being 'at home'. Although commentators emphasise the 'undeniably inaccessible' (DeSilvey 2007: 
417) and 'impenetrable' (Shanks 1992: 114) aspects of past materials, the incomplete biographies of second hand objects can also be imaginatively adapted towards the same end. In one example, a migrant artist living in London, purchasing second hand objects for his home, requested biographical information about them, collecting the fragmented stories into a book to share with visitors. He described how he 'borrowed' them as a way to 're-story the space, as well as reshape his own sense of home and identity'. These objects were imbued with histories which, in turn, were 'retrieved, usurped, and taken on as raw material for his life' (Lipman and Sheringham 2016: 53. See also Lipman forthcoming, Balthazar 2016, Jones 2010).

Such objects, however, are generally carefully chosen, In contrast, domestic residues draw attention to the spaces of home as previously inhabited, often by strangers. So whereas senses of homeliness may often involve the idea of a special, private and intimate relationship between home life and the material forms of domesticity, it is perhaps not unsurprising that anthropologist Daniel Miller dramatized being 'haunted' by feelings of anxiety about his home's material inheritance - both its original aesthetic and design, and the interior furnishings left by recent residents. Miller identified a problematic alienating 'discrepancy between the longevity of homes and the relative transience of their occupants' requiring a process of coming to terms with the 'agency expressed in the temporality of the home and its material culture' (Miller 2001: 107). But is the assumption correct that encounters with the home's tangible history will always be fraught? This essay suggests that people's affective relationship with the past of their homes is more ambiguous and complex, inflected through a diverse range of experiences, understandings and practices in which inhabitants negotiate awareness of prehabitation in multiple ways. The timbre of people's responses depends upon the type of object, where it is found, its assumed aesthetic, use or identity values, and its perceived cultural meanings. In particular, the location of materials within the home is an important consideration in determining responses. Participants encounter a range of traces of previous habitation - overt and subtle, surface and hidden, fixed and mobile. The home becomes a conglomeration of superficial surfaces and hidden depths, of spaces to store or archive objects and those to display them, of objects thrown away or lost, hidden things revealed - and others yet to be found.

Just as advice on house biographies emphasises the positive value of the temporal as well as temporary sharing of ownership or senses of belonging (Bushell 1989, Austin et al 1997, Barratt 2001, Backe-Hansen 2011), the home's inherited materiality can enhance senses of shared belonging with strangers whilst simultaneously requiring the negotiation of individual identity. The understanding of the home as shared over time leads to decisions informed by a framework of values balancing individual rights with an understanding of collective responsibility, the latter often reflecting a desire to preserve the home's past as part of an ethic of respect, care and custodianship.

\section{The etymology of the un/heimlich}

Intensifying responses to these objects is a sense that the home's past and its materials are imbricated with different degrees of agency. This is perhaps most dramatically rendered in the case of haunted homes, where experiences of a real sense of presence of the past often focus upon the figure of the ghost, who is assumed to be a previous inhabitant with continuing claims over their home, reinforced by the fact that uncanny events are often triggered after structural renovation work. Participants' feelings of belonging to home are challenged by such presences, and 'co-habiting' with ghosts requires strategies of negotiation ([Anonymous] 2014). Responses to inherited materials in homes where there are no direct experience of a ghost are nonetheless also infused with beliefs about their extended agency, with household practices suggesting people's need to engage different strategies, including at times rituals of appeasement and containment.

In his essay on the uncanny, Sigmund Freud offers a detailed analysis of the complex etymology of the now-archaic word heimlich, which, we are told, has two rather different meanings: a feeling of 
'home' - something cosy and intimate; and also, something concealed, out of sight, hidden or secret (Freud 2003 [1919]). This second meaning is known to Germans (my German mother-in-law offers the example of a secret recipe as having a heimlich quality). Freud is concerned to unpack the similarities between heimlich and its opposite - unheimlich, literally 'unhomely' (or uncanny in its approximate English translation). In his essay, Freud examines the relationship between these apparent opposite but closely intertwined states to develop a psychoanalytical theory explaining, with examples, the origin of feelings of unheimlich. Freud draws closely upon the work of the psychologist Ernst Jentsch, who, in a two-part paper published in 1906, had defined the unheimlich as a state of 'doubt as to the animate or inanimate state of things' (Jentsch, 1906, in translation). In Freud's paraphrase, unheimlich becomes 'intellectual uncertainty', something which is 'frightening precisely because it is not known and familiar' (Freud 2003 [1919]: 220). But this aspect of Jentsch's interpretation of the unheimlich does not satisfy Freud, who elaborates a psychoanalytical reading: the unheimlich becomes a particular 'class of frightening which leads back to what is known of old and long familiar'; specifically, 'something familiar that has been repressed'.

The cultural influence of Freud's essay is such that to speak of the un/heimlich for many evokes the psychoanalytical turn. This paper, however, returns in part to Jentsch; the close etymological coupling of the homely and unhomely, pivoting upon the relationship between what is occult and what is available, becomes a useful device for drawing attention to the relationship between the geographies of home and emotional responses to domestic inheritance. What is hidden concerns degrees of (or more accurately, the lack of) knowledge of earlier residents in the context of the close proximity to the objects they leave behind. Exploring the material inheritance of home in relation to definitions of heimlich and unheimlich helps locate the variety of responses to the past, of feelings of belonging and homeliness or of anxiety, superstition and uncertainty; often both. The home becomes an uncanny place because it holds secrets or hiding places (see Stewart 2003 and Fletcher 2000). The 'hidden' objects in this study become metaphors for a meeting of the heimlich and unheimlich, with the 'combination of the familiar and the unfamiliar' within the home rendering it uncanny (Gelder and Jacobs, 1998: 23) - akin to the experience of the spectres of the 'archaeological imagination', which are 'at once horrifying and comforting' (Buchli and Lucas, 2001: 11-12; see also Vidler 1999)

). Indeed, people's complex un/heimlich responses often relate to the relationship between the more hidden and more surface materials from the past - what is, in the literal sense, in or out of view; the metaphorical depths and surfaces of responses to the past are matched by visceral encounters and embodied practices. The spaces of concealment where some objects are found reflect the hidden identity of their original owners and the unknown social circumstances and intentions around the objects' concealment. And yet the process of discovery also confers belonging, a passing on of secrets, of intimate knowledge of the home's revealed layers. Where people choose to place such found objects also reinforces this overlapping of meanings. Removing objects out of sight - from display to storage - may signal their lack of value or, alternatively, their importance as things requiring protection. Such objects reinforce the heimlich - home as a safe place, of privacy, or a place to keep secrets - and simultaneously the unheimlich: home as unfamiliar, indeterminate, a place where there are secret, hidden things. Indeed, a focus on the afterlife of left behind materials positions the home as an entanglement of the heimlich and unheimlich, reinforcing inhabitants' role as custodians of what they both inherit and leave behind.

Metaphors of depth and surface have also emerged as a focus for debates about the value of heritage, with a growing unease with the 'salvage paradigm' - the desire to 'rescue something 'authentic' out of destructive historical change', and where authenticity 'always exists immediately prior to the present' (Clifford 2002: 160; see also MacDonald 2011). Rodney Harrison has argued for a move away from the 'modern conception of heritage' as 'salvage or preservation of that which is distant, old, hidden and hence authentic' in favour of an idea of heritage as a 'creative production involving the assembly and reassembly of things on the surface and in the present' (Harrison 2013: 227; see also Harrison 2011). At the level of people's everyday encounter with the past, it is clear that 
both ideas of heritage find expression. Indeed, the value granted to the role of the past underlies the choices participants feel able to make. The past is defined, on the one hand, in relation to degrees of distance from and difference to now, but also as an expression of the home's identity. Those who believe that the home's identity is reflected in its original design favour preservation: this is how it was intended to stand, this is what gives it its integrity. As one participant explained, her house was built as a 'whole object and if you're not careful it starts not to work properly. I don't like doing anything too drastic to an old house unless it's absolutely necessary'. But many people prefer the more progressive relationship to the past as fluid and evolving; the home's identity becomes an accumulation of contributions of generations of residents, a:

mix of different periods... I like the feeling of this house [having] been lived in for generations and each generation changes it. [It is] transition ... Houses change as people's needs change. [Too much preservation] And you wouldn't have a house anymore, you'd have a museum - because you wouldn't usually want to live in it

But the distinction between these two ideas is not always clear cut. Those who prefer a more progressive sense of history as evolving still tend to assume a greater value and respect for the older elements of their home, and older objects found within it. They will justify decisions to remove features by claiming they were not, in any case, original. But if identity is accumulative, this also lends weight to a belief that the process continuously confers agency from the past to the present. There is no linear time; the home is full of presences caught up in the lingering layers of a collective shaping of home. Within this entanglement of residents, agents and presences, its material objects require careful handling.

\section{Permanent features}

The home's material spaces also become a trigger for imagining previous occupants. Participants attempt to reconstruct the interior shape and function of their homes, to understand what people were doing within its spaces, and how they might have adapted to socio-economic conditions and to changing tastes, technologies and cultural norms. Those whose homes had not changed much found it easier to imagine previous lives; others expressed frustration, hunting for faint clues and traces of past configurations. The home's most enduring fixtures allow the most direct and unproblematic sense of relatedness with the past, the most benevolent and unthreatening sense of connection. Participants enjoyed the frisson of imaginative encounter with past residents through touching what had been touched by many before. Banisters, wooden beams, stone walls, for example, conjure up shared domestic routines, repeated reiterations of the intimate and ordinary. Walking up and down a staircase, opening doors, looking through windows - these become benign, transparent anchors between past, present and future, reinforcing ideas about touch as a means by which 'the distinction between past and present is momentarily dissolved' (Harries 2017: 110). The haptic tactility of these objects and their uncomplicated function also help to trigger the imagination. William, living in an Edwardian house in a south London suburb, reflected how, 'somebody's hand, many people's hands, have opened these [original brass handles on a back door] and gone out'

The act of walking up and down the stairs, holding onto a wooden banister that others would have touched for the same purpose, leads him to speculate about their lives within the house:

You do kind of think: how many people have come down the stairs? When have they come down the stairs? The banister - because it's so tactile I often think - how many people have been here?

Who were they? What were they doing? ... It's one of the most used spaces in the house, isn't it?

In a converted farmhouse in a remote Yorkshire hamlet, Pam described her love for the wooden beams in an upstairs room: 
I go in there and I stroke the beams because I love the fact that they've been there for 300 years. They were possibly part of something else before that ... It's a physical connection with the past ... Something about the number of lives that have been lived underneath them

These encounters lead participants to feel connected to a wider social lineage, as William added, 'It's a nice feeling. Of permanence - of being part of the world, I suppose. That other people have been here, and now I'm here, and other people will be here ... I'm part of this house'.

Looking out of the windows of her Victorian London semi to point to old trees, Rosemary reflected on how this made her feel a part of something bigger:

It's a sense of your place in the world ... Just knowing that you're not the beginning or the end. You're just a part of it, and it will continue. This house will be here after I'm dead. The house is like bigger than one human being ... A big line that goes back and it will go forward as well ... I still am there. I still am very connected. But I'm just - a little dot. Very connected and very belonging and everything else - but a little dot

This sense of the small, temporary nature of their own time leads participants to express a sense of obligation, of responsibility, to consider themselves their home's custodians, their duty to look after or improve it for the past and the future. One participant explained:

This [house] has been around for 180 years ... and it is this thing about being a custodian of it for the time being ... I'm improving the place ... The house deserves it, if you like ... We're making it better, mending it ... It's the same way you'd nurture a child, to come into this world and grow

Another stated: 'We very much feel that-you know, we're here for a bit. This house will go on. And - it's everybody's inheritance in a way ... We 're only custodians really'.

The more fixed materials allow connections which are unencumbered by more complex relationships or feelings, bleached of any of the messier visceralities of domestic life - and, for Pam, an urban escapee, of feelings of unease about the assumed disparities in wealth and comfort between her modernised farmhouse and the tough working lives of previous occupants. She said: 'Stone and wood don't come loaded with any guilt, do they, about how much easier one's life is now'.

\section{Surface objects}

These fixtures, then, create a benign relatedness to past and future residents via imagined shared domesticity creating an expansive sense of one's place in the sweep of time. But responses to found materials can be emotionally complex, reflecting an uncanny doubling of intimacy and unknowability. Some objects create particular unease. Inherited baths and beds, for example, are less tolerated. In contrast to bannisters and beams - where the frisson of shared touch occurs in the safety of neutral, public space - the feelings of vulnerability inherent in acts of bodily immersion and exposure make the imagined messy viscerality of past bodies too close. Joyce told me how she ordered her landlord to remove the beds in her semi-furnished rented flat in east London. She said: 'To actually sleep in someone else's bed, I mean ... I regard sort of my bed as my personal-it's me, it's mine ... It's a private space,

If energy from the past is believed to linger, those within such objects are less likely to be benign. Speculation about past events includes births and deaths (beds), and drownings, murders and suicides (baths). Participants are surprisingly specific in their conjecture; negative energy may wind itself down over time, but it may linger longer after slower, more painful deaths than swifter ones. 
Another form of materiality least likely to be tolerated - for different reasons - is the surface inheritance, the most superficial and often most recent additions - carpets, wallpaper, curtains, and the like. Participants seem to rather enjoy ripping these out, an initial ritual of claiming ownership. Inheriting what is deemed to be of poor taste offers the most leeway, the best justification for making changes. This allows people not only to substitute recent materials for those reflecting their own sensibility, but also, in a common justification, fulfils the custodial role of making improvements for the home itself, giving something back. As one commented:

They put in, you know, five pound chandeliers which vaguely looked as though they might just have been Victorian but quite patently were bought from Woolworths or equivalent. I wasn't going to do that

In the south London Edwardian semi, William was also quite scathing about what he inherited:

And they were sort of quite odd people ... You know - it had horrible wallpaper on the ceiling for some reason ... It didn't feel like sort of a warm, family house ... They had done up the house in a very, very, sort of shoddy way

But judgements about taste and quality are often tempered by an acceptance that tastes and circumstances change. William reflected with self-irony that future residents may well judge him in a similar light:

We are - the present incumbents. And in a couple of years' time we will move and somebody else will come and say, 'Oh my God, you'll never guess what, that's terrible. We'll have to get rid of that' ... And in ten years' time they may be sitting down speaking to an academic and going, 'God you'll never guess, we moved in here - the owners were very, very odd'

If the home's identity is deemed a palimpsestic accumulation, it is permissible to fit the home to one's own needs, circumstances and aesthetic choices - a far cry from Miller's dramatic complaint of inhibition and alienation. But decisions about what to keep or remove need to weigh personal judgements against the responsibility to establish the value of what is inherited - to distinguish what is superficial, mutable and of little intrinsic worth, from what has depth, endurance and meaning for the home's identity. This process is influenced by the social context. For William, for example, the previous residents were only considered 'odd' because of the way they had furnished the home. But elsewhere judgements are based upon rather more direct experience with previous residents. In a small Victorian terrace in central Bristol, Robert described the debris left behind by the previous owner: a broken chair, a pile of rubbish, a doll's arm stuck to a wall, and corks from multiple wine bottles. He also found hidden objects inadvertently left behind within a jammed-up drawer: bonehandled cutlery and a carving knife with a date on it ('a wicked looking thing'). Robert considered that the rubbish reflected the previous owner's chaotic lifestyle as an alcoholic, but also her relationship with him, which had soured since the exchange of contracts for reasons he could not fathom: 'She left a whole load of rubbish ... She stripped this place out. I mean, all she left was that broken chair ... my housewarming present!'

He could separate - or, as he said, 'dissociate' - the older objects from his feelings about the vendor because they had other qualities which set them apart. They remained unsullied; their biographies predated her; they are allowed to rise above the momentary social fracas.

Robert's story brings to mind Victor Buchli and Gavin Lucas' experimental use of archaeological categorisation techniques to explore left-over objects in a recently-abandoned council house, to gain insights into the social circumstances of previous residents. The process involved familiarity with the material cultures of home and an 'everyday ability to read it', alongside a 'more conventional application of archaeological methodology where understanding comes, ironically, by almost de- 
familiarising the house in terms of our everyday perception, and reconstructing it as an archaeological site' (Buchli and Lucas 2001: 160).

\section{Hidden objects}

Robert's ability to 'dissociate', however, differs from professional forms of de-familiarisation because it involves allowing the older objects a form of distinctive agency separate from the social context of which he is a part. For many participants, the meaning of inherited objects is imbricated in the personal process of making home. It is the manner of their arrival which often shapes participants' encounters with these objects and dictates their afterlife. Beyond inherited material fixtures and superficial decor, participants describe how they stumble upon hidden objects, often inadvertently during the peeling back of the home's layers during renovation. Such finds emerge as a by-product of, and during absorption within, ordinary homemaking practices, an effect of an intimate engagement with the home as a material artefact. Its hidden layers release un/heimlich affects, yielding up secrets - what lies behind, beneath, above - whilst simultaneously suggesting others. These finds constitute chance encounters which also remind occupants that the project of making home cannot be completely controlled. Isabella, living in a sixteenth century manor house outside Bristol, recalled:

We had to do a bit of mending ... and we were finding things which we hadn't deliberately set out to do - underneath. By mistake. We don't look for things. It's like doing some kind of puzzle. Every now and then you get another piece ... We know there's a staircase behind there because Georgie [the dog] found it ... found a squirrel's nest underneath the wood. They had filled it up with stones

Elsewhere, in the Victorian semi in south London, Sharon recalls the excitement of uncovering an original fireplace:

Adam said: 'Oh there is just this bit of wood ... there is no point taking that off, there will be nothing under there'. I was like: 'Get it off! Get it off completely!' Cast-iron, original fireplace underneath it ... Amazing! It felt like I had uncovered a mummy from the pyramids or something ... it was completely intact, you know ... [We also found] wallpaper in one of those built-in cupboards ... It was definitely Victorian because it was hand painted. It's like an archaeological find

But if participants express a sense of custodial responsibility for dealing correctly with this accidental archaeology, they accept the irony that much of what they find might also have been left accidently or without too much thought. Isabella explained that the preservation of her house was down to happenchance. For many centuries the house was rented out, probably to poor relations: 'And that's why it's interesting. Because people do not remove, you know - put fresh things in ... All those periods of time, people just did what they had to do [which] preserved the interesting things'.

Sharon also reflected on the fact that the fireplace had been covered over probably because someone thought it was ugly and it was the cheapest and most expedient solution; and the wallpaper had been preserved because 'people didn't take time in cupboards'. These circumstantial explanations for why certain artefacts are preserved lends weight to critics of those who appear to value the 'authenticity' of old things just because they are old. Certainly, participants tend to respond differently to objects which they assume were intended to be discarded. Ubiquitous pottery fragments dug up in gardens are greeted with the most playful response, often creatively remodelled as mosaic art - reworking fragments with unknown histories into new, knowable and unthreatening things. 


\section{Rituals of retention and reburial}

And yet it is telling that the pottery is retained and displayed in these homes, albeit in a reappropriated form. Indeed, a significant proportion of found objects, whatever their assumed pedigree, provenance or intention for being left, are retained within the home and done so carefully, knowingly and with degrees of respect. The process of retrieving left-behind things might create a sense of intimate connection with the home, of being let into its secrets. But, erstwhile hidden objects invisible, waiting presences of and from the past - are, once exposed, granted a degree of agency, placed into a special category of meaning beyond (even if also involving) their more ordinary aesthetic, monetary or use values. The nature of these objects requires a particular form of handling perhaps more so if previous inhabitants are assumed to have lacked a sense of custodianship, or did not have the privilege, money or time to have such concerns. Either way, as part of the home's accumulated identity they need to be retained within the home. The manner of their storage contrasts with the way participants store (or hoard, as some apologetically suggested) personal items. During guided tours of their homes, I would sometimes be politely turned away from a closed door - often a box room or children's room no longer in use. In a cottage in Marlow, Karen joked that she called hers the 'Room of Doom' which was full of objects 'in transition'. Where were they in transition to? She didn't know, but they had been there long enough to be granted the status of 'transitional objects', in a state of perpetual anticipation - a haphazard form of domestic archive mixing past memories with the potential of future function.

In contrast, the storing of found objects takes on a different set of meanings. Many participants squirrelled these away into boxes and envelopes, placing them out of sight in cupboards, drawers, attics, scrapbooks: a kind of ritual of reburial. These practices appear to be part of the negotiation of shared ownership, a form of appeasement as well as of containment of the past. These practices included retaining original elements of the house that had been replaced, such as 'beautiful' Victorian windows deposited into a cellar, or a fragment of (disliked) wallpaper into a scrapbook, a part standing for the whole. Sometimes storage is a way of protecting delicate things, such as a piece of crumbling ancient wall left in a bag in a drawer; at others, it is to protect the residents themselves, who express anxiety about proximity to lingering contamination: 'And then I thought, 'Oh god'. I'd read about how these wallpapers [and paint] had arsenic on them and things'.

Grace, an antiques dealer, showed me a number of choice items displayed in glass cabinets in her Georgian house along a major road in south London. She also described a box she kept in an inaccessible compartment, behind the cabinets, which contained hidden objects which had been 'thrown up' by the shaking of the ground, before the front drive was tarmacked, as heavy vehicles thundered past. She explained: 'It would throw up things like clay pipes. I found a gold ring, coins, bones, all sorts of bits and pieces ... You'd go out and you'd suddenly see a ring ... I found lots of $16^{\text {th }}$ and $17^{\text {th }}$ century pottery'.

The secret compartment reflected her relationship with these objects. In contrast to her antiques proudly displayed in the cabinets, the found objects were not to be admired for any aesthetic quality or worth. They did not need to be seen or touched at all, but they did need to be kept somewhere in the house. In this way, Grace respected but contained the past, literally 'keeping it in its place'. Such an act of hiding, storing or archiving has a symbiotic relationship with the decorations, features and objects displayed and designed to be looked at. Being placed out of sight does not trouble the aesthetic and functional choices involved in present-day homemaking. In this sense found objects are granted less value. And yet, if the 'past is immanent in our embodied engagement with [the] world' (Harries 2017: 126), we also need to account for those objects which we do not wish to touch with hands or eyes, that we need to keep present and close, but contained. This may be an attempt to diminish their agency, but keeping them out of sight within the home also grants them more power, reinforcing their mystery and enacting an acknowledgement that they contain a special relationship to the home. 
Removing unwanted inherited objects out of sight to a lesser-used room is another way of balancing the need to respect found objects as part of the home's identity with the project of reinforcing belonging through displayed personal objects. Janet had taken a much-loved fireplace with her from home to home, removing the original fireplace in the living room to accommodate it. She expressed a certain guilt for doing so, but explained that she had compromised by moving the original feature into her bedroom upstairs, where she didn't have to look at it as much. She added defensively: 'At least it is still in the house'.

Participants also re-conceal objects for future residents to discover - another form of compromise between custodianship and taste - as one participant explained, pointing to original fireplace tiles that she disliked:

None of it is damaged, it's all behind there ... I've just painted over them. Somebody else might like them...

Nothing is gone. It's for the future. I'm only a guardian

Ritual objects

But some objects are set apart further, inherited with edicts attached dictating that they must be left untouched, in situ. The value of these objects is often transferred orally via people granted authority: previous inhabitants, older family members and local experts. Many participants were vague about the exact provenance of such a practice, but there was a suggestion of anxiety surrounding these objects, having been granted special agency or status - an unspoken, veiled, threat of some reversal of fortune if the object is removed. In such cases no negotiation is possible. Responses to these objects have been pre-established and passed on; participants easily succumb to the pressure to continue the tradition, often without enquiring why. A sense of custodianship, in these examples, becomes loaded, a burden.

In one example, Susan, living in a 1930s semi in suburban Ipswich, found a little plastic cat on a window sill when she moved in. She explained:

I don't move it. It stays there ... My mum always said: 'If you find something when you move into your house, you must keep it. And if you leave the house, you should leave it there' ... There was a silk scarf, and an ornament. And [mum] wrapped the ornament in the silk scarf and put it carefully in the loft. She left it with a note to say that it must never leave the house ... When we found the little cat - she said: 'Oh, you must leave that there. You mustn't get rid of that'

In an early nineteenth century house in south Manchester, the owners inherited a painting of a man, which they were told was at least a hundred years old, came with the house and needed to stay where it was. They did not seem curious to know who he was, but tellingly, they gave him an unthreatening nickname - he is known as Uncle Toby. However, elsewhere, objects reflecting an assumed previous ritual function create the most anxiety. Divia found a shoe, placing it in the attic of her seventeenth century house in a southern English town. She said: 'We took it down and then someone said that shoes are left in houses to bring luck and to protect the house. We put it back in a round balsa wood box that we had'.

A 'cluster' of other finds had been collected in the box since - an old photograph, a newspaper dated 1943 - but as she explained:

The shoe has overarching significance. The other things gather and I think the shoe has to be there. Being asked by you about it, I feel nervous. I don't really want to even get it out. It feels embedded in the house. Part of its fabric and not something that should be meddled with ... Leave well alone 
... We will leave it there and tell the new owners that it is there - hand it on as something to be known about

These three examples represent one end of a spectrum of practices suggesting a belief in found objects' continuing agency. They point to tantalising continuities of oral traditions of belief which reiterate previous ritual roles of objects (particularly between the seventeenth and nineteenth centuries) to protect against evil spirits at a home's weak spots (Billingsley et al 2017) - practices which, perhaps, find their counterparts in other continuing but mutating traditions, such as cementing objects behind corner stones or into foundations to bring luck or ensure the home's physical strength, and the craze for more diffusely located time capsules - the latter reaching a peak during the futureoriented 1950s. If participants believe the intention is to protect, these objects are granted the most respect - handled with greater sensitivity, ensuring that the tradition - whoever started it and for what purpose - continues in some form. Some participants, indeed, created their own versions of these practices, leaving mint coins under floorboards to mark the year they moved in; placing a tin box into the setting concrete foundations containing coins and newspapers. Both marked a moment: a contribution to a home's birth or rebirth. Presumably these were not meant to be found, or at least won't be until the homes are refurbished or demolished. The act might be a kind of embodied prayer for the foundations to hold fast or to reinforce a sense of pride and belonging in the home. Perhaps this is why such objects are treated so respectfully when they are later discovered. Alternatively, there is for some the pleasure of depositing objects that may one day be found. Peter, a carpenter, described a 'long-standing builders' tradition' of leaving things in the crevices of walls - initials, names, dates, newspaper - in order both to exchange practical information ('this is when the building was last modified'), but also to celebrate the sense of being part of a particular lineage:

As you build you find these things - and go 'Ah, I'll do that myself. I quite like that' ... It's a little storytelling tradition. There is a genuine pleasure in finding evidence of another man's work ... Why would you leave a note with your name and the date if it wasn't to say: 'I did this, at this time. And I feel a value attached to that' ... Even though you're not going to receive the compliment, it's the idea that a builder in the future will open up what you've done, find your name, and compliment you in his own mind

Conclusion

Peter's celebration of the secret, exclusive act of leaving banal objects during practices of stripping down, mending, adding back a building's layers, is an exchange of conversation over time, part of a chain link of embodied relatedness - a passing on of knowledge and the conditions for acknowledging work done. It doesn't matter if you are long dead when the next person discovers what you have left (or that they are long dead when you discover theirs). What is important is that these practices taking place in the same place, with the same care - are shared.

For residents, likewise, encounters with material residues require an admission that the idea (or ideal) of home as something personal or private needs to sit alongside the fact it is also inevitably a collective endeavour. This broader temporal pantheon of habitation is most vividly manifest in the material traces marking out the erratic, mutable, history of homemaking practices over generations. The special values granted to what remains as intimate conduits between the past and future makes the task of homemaking more complex. At the most abstract level, a frisson of awe is sparked by the thought of the shared touch of the home's fixed objects, fuelled by a desire to experience something bigger than the self, something which endures. But the sense of temporariness of belonging this triggers also creates the burden of respectful engagement with the home, an ethical code of custodial responsibility and duty of concern for other residents, whereby homemaking practices become choices that need to be justified. Such decisions need to negotiate the desire for personal space alongside the duty to make the 'right' decision for the home itself, be that to discard, retain or rebury objects. These belong to the home, express its accumulated identity, and therefore require accommodation. Even 
objects which were likely lost, thrown away or left purely for fun, are deemed to contain or release something from the past, something of that essence of 'me, here, now' - whoever, wherever and whenever that was. Exploring where disparate forms of material residue are encountered, handled and placed - the more recent, surface layers, or the mobile things left, lost or purposefully hidden illuminates the different values underpinning such decisions, offers insights into the relationship between historical and homemaking practices, and how the past and its material residues are imbricated in social relationships (imagined or otherwise) through which people decipher or reinvent cultural meaning.

Considering the home as a site of historical practice and imagination extends recent interest in landscape as 'processual', where 'different temporal rhythms - past and present, creation and disappearance - are held in tension ... [and] everyday landscapes are implicated in the negotiation of the past and the present' (Hanlon, Hostetter and Post 2011:2). The complexity of participants' engagement with inherited objects speaks back to any simplified binary between metaphors of surface and depth, bypassing reaction or counter-reaction when one is deemed too privileged over the other. Importantly, accounting for a sense of the past's extended presence also requires that we acknowledge the possibility that, within the ordinary Western home, some past objects are granted forms of what might be broadly categorised supernatural agency, and that folkloric beliefs and rituals continue to shape modern homemaking. The accidental discovery of ritual objects causes particular anxiety, and participants are keen to keep them in situ rather than risk reducing or disturbing their power. But people also seem quick to create or accept ad hoc prescriptive edicts to retain objects which do not have obvious original ritualistic function - assuming other-worldly agency for mundane things, including the little mass-produced plastic cat that probably fell out of a Christmas cracker. This raises the question: can our material theories account for or accommodate such beliefs, experiences and practices?

Mitch Rose, for one, has derided material cultural theory's apparent 'profoundly secular' forms, where, he argues, the 'co-constitutive relation' between subjects and objects privileges the 'present and productive over the absent and silent', trapping relations 'within a set of banal everyday processes' (he points out that material structures often stand for absences) (Rose 2011: 110). Of course, as this essay shows, he is wrong about 'banal everyday processes', pointing as it does to the capacity for the unheimlich, as the strange within the familiar, to include the most seemingly ordinary objects and homemaking practices. These modern Western domestic interiors are alive with mundane things granted unearthly powers; wider senses of time and space are caught up in the temporary, small-scale practices of the everyday. But such objects take their place within a more complex expression of degrees of absence and presence, such as, for example, that described as the 'paradox of absence-presence experienced through bereavement' (Maddrell 2013: 503), where a sense of 'ongoing presence of the deceased' is 'often expressed as continuing bonds' (ibid: 517). This essay has explored the material traces of those now-absent others of the home's past, given that 'while absence is matter out of place, it is still placed through matter' (Meyer, 2012: 109). To understand how the unheimlich and heimlich are imbricated is to accept a suggestion that immaterial forces are believed to persist within the material (not just objects which stand for absent others). It might be easiest to account for such forces as imaginative responses to the past; it is not of course that plastic cats have actual agency, it is just that people continue to attribute agency to them within particular contexts. Indeed recent work appears to allow a degree of agency for objects, encouraged by a focus on the lively, excessive and emergent nature of the material world (see Anderson and Wylie 2009, Dewsbury et al 2002, Kearnes 2003, Latham and McCormack 2004), as well as their broader relationships - the way 'different configurations of objects, technologies, and (human and nonhuman) bodies come together to form different capacities and experiences of relationality' (Edensor 2012: 1105).

But there are limits to such liveliness; objects are not allowed to be too animate. Rather than critiquing materialism, many are at pains to reinforce it despite appearing to grant the object world more agency than ever (Doel 2004). This has not gone unnoticed, with some questioning the recent 
influence of Alfred Gell's ideas in which an object's agency is limited to social action, which 'excludes... factors that make it possible ... to conceive of certain objects as having agency in themselves' (Morphy 2009: 14; see Gell 1998, Fowler and Harris 2015). Others are returning to Jane Bennett's (2001) theory of enchantment, which suggests that 'through certain engagements with materialities people can be enchanted' (Burrell 2010: 143), accounting for the 'sheer emotional, imaginative and tangible power that objects provoke around them, and asserts people's openness to the different and unusual' (ibid: 144). Bennett's concept of enchantment 'recognises qualities of liveliness as internal rather than supplementary to objects, helping move beyond the assumption that objects simply await enlivening by human subjects' (Ramsay 2009: 198), alongside a 'capacity of materiality to work in unpredictable ways' (199).

It is not that we should turn away from a critical examination of relationships between the material, social and cultural - in some ways there is no other project available. But if we are to do justice to the beliefs that underlie people's responses to certain objects, we might have to accept challenges to the 'inherited cultural categories that limit the questions and interpretations we bring to our research' (Brown and Walker 2008: 297). Indeed, refusing to accept 'animism and non-human agency ... devalues peoples' lived experience' (ibid).

For both Jentsch and Freud, this idea would be repugnant. Jentsch points to the 'horror which a dead body (especially a human one), a death's head, skeletons and similar things cause' as explained 'by the fact that thoughts of a latent animate state always lie so close to these things' (Jentsch 1906, translation). Making use of this observation, Freud's psychoanalytical ideas of the unheimlich countered animism and 'primitive' belief in spirits. Such beliefs, as well as the resultant uncanny responses to objects, were already pathologised by Jentsch in relation to particular susceptible individuals: 'women, children and dreamers' (See Blackman and Walkerdine 2001; and for more recent iterations: Green 1973; Greeley 1975). Freud, in turn, reflected upon the 'strength of our original emotional reaction to death' - the 'primitive fear' of which is 'so strong within us and always ready to come to the surface on any provocation' (Freud 2001 [1919]: 242). It is this, in part, which turns 'something frightening into something uncanny' (243). In this reading, the agential power of found objects might be explained by their association with the dead - the discovery of found objects, and their intimate sensory presence, 'provoking' feelings of return to a repressed original fear. Such an interpretation, however, places limits on the complexity of people's responses to the material past. If the uncanny 'eludes coherence', representing 'that which exceeds the control of the agents of reason' (Bennett and Royle, 1995: 39; see Wolfreys 2002; Ellison, 2001), it is in part because it is 'bound up with an experience of the uncanny', which 'disturbs any attempts to remain analytically detached and objective'.

The context in which that experience takes place also requires scrutiny. When studying amulets exhibited at the Wellcome Collection, Jude Hill noted that the manner of their display in glass cases was designed to subdue their 'latent' magic powers by categorising them as objects of archaic, premodern value within a 'narration of a broader scientific progress' (Hill 2007: 75). And yet, she argued, the museum 'could not expunge' their magic, and their containment in archives merely seemed to increase their power rather than remove it. As this essay has shown, such experiences have particular impact within the non-institutional context of homes and daily life. Tracing the responses to the home's material inheritance requires us to consider how attempts to contain beliefs about objects within the particular explanatory strategies we allow for them may well increase their power to unnerve, to overspill our categories in good, old-fashioned uncanny ways.

\section{References}

Anderson B and Wylie J (2009): 'On Geography and Materiality'. In Environment and Planning A (41): 318-335

Austin D, Dowdy M and Miller J (1997): Be Your Own House Detective. BBC Books, London 
Backe-Hansen M (2011): House Histories: The Secrets behind your Front Door. The History Press, Stroud

Barratt N (2001): Tracing the History of your Home. Public Record Office, Richmond, Surrey

Bennett J (2001): The Enchantment of Modern Life: Attachments, Crossings, and Ethics. Princeton

University Press, Princeton

Balthazar A (2016): 'Old things with character: The fetishization of objects in Margate, UK'. Journal of Material Culture 21.4: 448-464

Bennett A and Royle N (1995): An Introduction to Literature, Criticism and Theory: Key Critical

Concepts. Prentice Hall/Harvester Wheatsheaf, Hemel Hempstead

Billingsley J, Harte J and Hoggard B (2017): Transactions of the Hidden Charms Conference 2016.

Northern Earth Books, Hebden Bridge

Blackman L and Walkerdine V (2001): Mass Hysteria: Critical Psychology and Media Studies.

Palgrave, Basingstoke

Blunt A and Dowling R (2006): Home. Routledge, Abingdon

Brown L and Walker W (2008): 'Prologue: Archaeology, Animism and Non-Human Agents'. Journal of Archaeological Method and Theory 15: 297-299

Buchli V and Lucas G (eds.) (2001): Archaeologies of the Contemporary Past. Routledge, London Burrell K (2011): 'The enchantment of western things: children's material encounters in late socialist

Poland'. Transactions of the Institute of British Geographers 36: 143-156

Bushell P (1989): Tracing the History of your House. Pavilion Books, London

Clifford J (2002): 'The Others: Beyond the 'salvage' paradigm'. Third Text Reader on Art, Culture

and Theory (eds.) R Araeen, S Cubitt, Z Sardar. London, Continuum: 160-165

DeSilvey C (2006): 'Observed Decay: Telling Stories with Mutable Things'. Journal of Material

Culture 11.3: 318-338

DeSilvey (2007): 'Salvage Memory: constellating material histories on a hardscrabble homestead'.

Cultural Geographies 14

Dewsbury J, Harrison P, Rose M and Wylie J (2002): 'Enacting Geographies'. In Geoforum 32.4: 437-440

Digby S (2015): 'The Casket of Magic: Home and Identity from Salvaged Objects'. Home Cultures:

The Journal of Architecture, Design and Domestic Space 3.2: 169-190

Doel M (2004): 'Poststructuralist Geographies: The Essential Selection'. In Cloke P, Crang P and M

Goodwin (eds.) Envisioning Human Geographies. Edward Arnold, London, 146-171

Edensor T (2012): 'Illuminated atmospheres: anticipating and reproducing the flow of affective

experience in Blackpool'. Environment and Planning D: Society and Space 30: 1103-1122

Ellison D (2001): Ethics and Aesthetics in European Modernist Literature: From the Sublime to the

Uncanny. Cambridge University Press, Cambridge

Fletcher J, (2000): 'The Haunted Closet'. In Textual Practice 14.1: 53-8

Fortier A-M (2000) Migrant Belongings: Memory, Space, Identity. Berg, Oxford

Fowler C and Harris O (2015): 'Enduring relations: Exploring a paradox of new materialism'. Journal of Material Culture 20.2: 127-148

Freud S (2003 [1919]): The Uncanny. Penguin Books, London

Gelder K and Jacobs J (1998): Uncanny Australia: Sacredness and Identity in a Postcolonial Nation.

Melbourne University Press, Melbourne

Gell A (1998): Art and Agency. Oxford: The Clarendon Press

Greeley A (1975): The Sociology of the Paranormal: A Reconnaissance. Saga Publications, Beverly

Hills

Green A (1973): Ghost Hunting: A Practical Guide. Mayflower, St Albans

Gregson N and Crewe L (2003): Second-hand Cultures. Berg, Oxford

Gregson N, Metcalfe A and Crewe L (2007): 'Identity, mobility, and the throwaway society'.

Environment and Planning D: Society and Space 25: 682-700

Grossman A (2015): 'Forgotten Domestic Objects'. Home Cultures: The Journal of Architecture,

Design and Domestic Space 12.3: 291-310

Hanlon J, Hostetter E and Post C (2011): 'Special Issue Introduction: Everyday Landscapes: Past and Present, Presence and Absence'. Material Culture 43.2: 1-5 
Harries J (2016): 'A Stone that feels right in the hand: Tactile memory, the abduction of agency and presence of the past'. Journal of Material Culture 22.1: 110-130 Harrison R (2013):

Heritage: critical approaches. Routledge, London

Harrison R (2011): 'Surface assemblages. Towards an archaeology in and of the present'.

Archaeological Dialogues 18.2: 141-161

Hetherington K (2004): 'Secondhandedness: consumption, disposal, and absent presence'.

Environment and Planning D: Society and Space 22: 157-173

Hill J (2007): 'The Story of the Amulet: Locating the Enchantment of Collections'. Journal of Material Culture 12.1: 65-87

hooks, b (1990) Yearning: Race, Gender, and Cultural Politics. South End Press, Boston

Jeffries N, Owens A, Hicks D, Featherby R and Wehner K (2009): 'Rematerialising metropolitan histories? People, places and things in modern London'. In M Palmer and A Horning (eds.) Crossing Paths or Sharing Tracks: Future Directions in the Archaeological Study of post-1550 Britain and Ireland. Boydell and Brewer, Woodbridge: 323-50

Jentsch E (1906): 'On the Psychology of the Uncanny'. Psychiatrisch-Neurologische Wochenschrift 8.22 (25 Aug. 1906): 195-98 and 8.23 (1 Sept. 1906): 203-05. Available in English translation by Roy

Sellars at: http://www.art3idea.psu.edu/locus/Jentsch_uncanny.pdf

Jones S (2010): 'Negotiating Authentic Objects and Authentic Selves: Beyond the Deconstruction of Authenticity'. Journal of Material Culture 15.2: 181-203

Kearnes M (2003): 'Geographies that Matter - The Rhetorical Deployment of Physicality?' Social \& Cultural Geography 4.2: 139-152

Kingsbury P and Pile S (eds.) (2014): Psychoanalytic Geographies. London: Routledge

Latham A and McCormack D (2004): 'Moving Cities: Rethinking the Materialities of Urban

Geographies'. In Progress in Human Geography 28.6: 701-724

Lipman C, Co-habiting with Ghosts: knowledge, experience and belief and the domestic uncanny (2014). Routledge, London

Lipman C (forthcoming): Heritage in the Home: Domestic Prehabitation and Inheritance. Routledge, London

Lipman C and Sheringham O (2016): 'Restor(y)ing Home: Reflections on Stories, Objects and Space in Balin House Projects'. In T Khonsari (ed): My Home is Your Home. London: Public Works Publishing: 52-61

MacDonald F (2011): 'Doomsday fieldwork, or, how to rescue Gaelic culture? The salvage paradigm in geography, archaeology, and folklore, 1955-62@. Environment and Planning D: Society and Space 29: 309-335

Maddrell A (2013): 'Living with the deceased: absence, presence and absence-presence'. Cultural Geographies 20.4: 501-522

Marcoux J-S (2001): 'The Refurbishment of Memory'. In (ed.) D Miller: Home Possessions. Berg, Oxford: 69-86

Marcus C (1995): House as a Mirror of Self. Conari Press, Berkeley

Meyer M (2012): 'Placing and tracing absence: A material culture of the immaterial'. Journal of Material Culture 17.1: 103-110

Miller D 2001: 'Behind Closed Doors'. In D Miller (ed.) Home Possessions: Material culture behind closed doors: Berg, Oxford

Miller D (2008): The Comfort of Things. Polity Press, Cambridge

Morphy H (2009): 'Art as a Mode of Action: Some Problems with Gell's Art and Agency'. Journal of Material Culture 14.1: 5-27

Owens A, Jeffries, N, Featherby R and Wehner K (2010): From the Unusual to the Banal: The Archaeology of Everyday Life in Victorian London. Museum of London Archaeology Research Matters 4. Museum of London: London

Ramsay N (2009): 'Taking-place: refracted enchantment and the habitual spaces of the tourist souvenir'. Social \& Cultural Geography 10.2: 197-217

Rose M (2011): 'Secular materialism: a critique of earthly theory'. Journal of Material Culture 16.2: 107-129 
Shanks M (1992): Experiencing the Past: on the character of archaeology. Routledge, London Stewart V (2003) Women's Autobiography: War and Trauma. Palgrave Macmillan, New York Tolia-Kelly D (2004): 'Locating Processes of identification: Studying the Precipitates of Re-memory through Artefacts in the British Asian Home'. Transactions of the Institute of British Geographers 29: 314-329

Varley A (2008): 'A Place Life This? Stories of Dementia, Home, and the Self'. Environment and Planning D: Society and Space 26: 47-67

Vidler A (1999) The Architectural Uncanny: Essays on the Modern Unhomely. MIT Press, London Wolfreys J (2002): 'Undoing London or, Urban Haunts: the Fracturing of Representation in the 1990s'. In Gilbert P (ed.) Imagined London. State University of New York Press, Albany, 193-217 